\title{
El desarrollo constitucional de los derechos indígenas en el Ecuador
}

\section{The constitutional development of indigenous rights in Ecuador}

\author{
Rosa Leonor Maldonado-Manzano \\ ub.rosamaldonado@uniandes.edu.ec \\ Universidad Regional Autónoma de los Andes, Babahoyo \\ Ecuador \\ https://orcid.org/0000-0002-0083-3227 \\ Stephanie Bravo-Urrutia \\ db.stephanieybu@uniandes.edu.ec \\ Universidad Regional Autónoma de los Andes, Babahoyo \\ Ecuador \\ https://orcid.org/0000-0002-5023-5209 \\ Jennifer Andrea Bravo-Zapata \\ dn.jenniferabz@uniandes.edu.ec \\ Universidad Regional Autónoma de los Andes, Babahoyo \\ Ecuador \\ https://orcid.org/0000-0002-7567-4400 \\ Lisbeth Sánchez-Guilindro \\ db.lisbethcsg97@uniandes.edu.ec \\ Universidad Regional Autónoma de los Andes, Babahoyo \\ Ecuador \\ https://orcid.org/0000-0003-0082-8636
}

Recepción: 15 de septiembre 2021

Revisado: 25 octubre 2021

Aprobación: 15 de noviembre 2021

Publicación: 01 de diciembre 2021 


\section{Estimado Editor (a):}

Los pueblos indígenas, fueron los primeros habitantes, en el territorio ecuatoriano, ellos conservan su cultura, vestimentas e inclusive su forma de vivir, por lo que no se debe hacer a un lado sus derechos como habitantes porque todo habitante del territorio ecuatoriano gozará de los derechos establecidos en la Constitución, la ley suprema. La cultura indígena es muy diversa desde su ropa, la comida, entre otros (Padrón, 2006). La armonía con la naturaleza es forma de admiración, su territorio no debe de ser invadido por personas ajenas, porque ellos deben conservar su cultura ancestral.

Cabe mencionar que a lo largo de la historia han existido veinte constituciones la primera en el año de 1830 y la última en el 2008 y recién en la décimo novena constitución se consagra los derechos de los indígenas lo cual entra en vigor con la posesión del presidente Jamil Mahuad Witt por consecuencias de revueltas asumió la presidencia Gustavo Noboa Bejarano entre estos conflictos en la carta magna los grupos étnicos se nacionalizan, amplía los derechos económicos-sociales incrementando sus beneficios a los grupos vulnerables además la conformación étnica y cultural incluyendo los principios pluricultural y multiétnico. Los pueblos indígenas han ido posicionando sus derechos en las legislaciones y la institucionalidad de los Estados, en un proceso dificultoso, que continúa en el presente. (Doyle, 2015)

El Convenio No. 169 de la OIT sobre Pueblos Indígenas y Tribales en Países Independientes (en adelante el Convenio) fue ratificado por el Ecuador el 15 de mayo de 1998 y entró en vigencia el 5 de septiembre de 1991 (Organización Internacional del Trabajo, 2014). La Declaración de las Naciones Unidas sobre los Derechos de los Pueblos Indígenas (en adelante la Declaración) fue adoptada por la Asamblea General el 13 de septiembre de 2007, con el voto favorable de 143 estados, entre ellos Ecuador.

Por medio de la historia en el ámbito político sabemos que se han desarrollado veinte constituciones y estas con diversas formas de aplicar la ley, continuando con el ordenamiento jurídico, recién en la constitución de 1998 se agregaron los derechos colectivos de los pueblos indígenas, esto causó que se reconozcan la forma de 
organización, sus territorios ancestrales y sus tradiciones. Es en este punto donde surge el derecho a la participación de indígenas, ya que el Ecuador desde entonces, se ha convertido en un país multiétnico y pluricultural.

Por ello, los pueblos y nacionalidades se encontraban perteneciendo a una nación que no era la suya, ocupando una condición de minorías culturales, lingüísticas o étnicas y en ocasiones con un territorio dividido por fronteras. (Bauer, 2020). El contenido del derecho indígena responde a un proceso de identidad cultural, construido durante miles de años, sobre la base de su cosmovisión, esto es, de la manera en que ellos entienden e interpretan el mundo. Tiene un profundo sentido humanista de respeto entre ellos, pero, además, de convivencia armónica con la naturaleza, lugar donde empieza y termina la vida.

A los pueblos y nacionalidades indígenas se le vulneraban sus derechos constitucionales tratándolos como una raza de menor jerarquía por el simple hecho de ser indígenas, a partir de la constitución del 1998 se reconocieron los derechos constitucionales de los indígenas y se acoge al Convenio 169 de la OIT, el reconocimiento por parte del Estado del derecho indígena no ha sido pacífico, todo lo contrario, se ha ido construyendo a través de la lucha de sus pueblos, incluso con derramamiento de sangre, pues, muchos de sus líderes han sido victimados en el desarrollo de tal proceso.

En este orden de ideas, la jurisdicción indígena y sus procedimientos forman parte de la identidad cultural de los pueblos y nacionalidades indígenas, cuyas prácticas se realizan cientos de años antes de la llegada de los españoles a continente americano. Por ende, los homicidios, asesinatos y demás "infracciones graves", siempre han sido resueltos con base en sus costumbres y derecho consuetudinario.

Por otro lado, la justicia ordinaria y la justicia indígena pueden convivir armónicamente en nuestra sociedad, siempre y cuando el Estado cree las condiciones para que ello suceda. Tales condiciones tienen que ver, principalmente, con el respeto irrestricto a la decisión de sus autoridades. Recordemos que las resoluciones de la justicia indígena se realizan con la participación de sus integrantes, es decir, no son 
decisiones arbitrarias que responden al criterio de una sola persona, todo lo contrario, se adoptan en consenso.

\section{FINANCIAMIENTO}

No monetario.

\section{AGRADECIMIENTO}

A la Universidad Regional Autónoma de los Andes, Quevedo, por motivar el desarrollo de la Investigación.

\section{REFERENCIAS CONSULTADAS}

Asamblea Nacional Constituyente de la República del Ecuador, (2008). Constitución de la República del Ecuador. [Constitution of the Republic of Ecuador]. Montecristi. Registro Oficial 449 de 20-oct-2008. Recuperado de https://n9.cl/sia

Bauer, O. (2020). La cuestión de las nacionalidades. 352. Ediciones Akal

Doyle, M. (2015). Debates y demandas indígenas sobre derechos a la comunicación en América Latina. Temas Antropológicos. Revista Científica de Investigaciones Regionales, 37(2), 89-118.Recuperado de: https://n9.cl/jbqfu

Padrón, R. A. (2006). La autoestima en la cultura indígena chatina de México. Mendive, 4(2), 110-117.Recuperado de: https://n9.cl/d6o8f

Organización Internacional del Trabajo. (2014). Convenio Núm. 169 de la OIT sobre pueblos indígenas y tribales en países independientes. Declaración de las Naciones Unidas sobre los Derechos de los Pueblos Indígenas. Lima: OIT/Oficina Regional para América Latina y el Caribe. Recuperado de: https://n9.cl/jkso 